\title{
Casa do Kukurro - tradição cultural e sua influência na amplificação e manutenção da diversidade em uma roça
}

\author{
Fábio de Oliveira Freitas* \\ Sandra Beatriz Barbosa de Cerqueira Zarur*
}

\begin{abstract}
FREITAS, F.O.; ZARUR, S.B.B.C. Casa do Kukurro - tradição cultural e sua influência na amplificação e manutenção da diversidade em uma roça. Revista do Museu de Arqueologia e Etnologia, São Paulo, 17: 381-389, 2007.
\end{abstract}

Resumo: Este trabalho apresenta pela primeira vez uma tradição cultural, a qual possui forte impacto na diversidade alimentar manejada por índios do parque indígena do Xingu. A “casa do Kukurro”, ou casa do espírito da lagarta consiste na construção de dois montes ou covas nos quais todas as variedades de mandioca - Manihot esculenta Crantz manejadas pelo agricultor ficam reunidas. A crença é de que esta prática fortalece a energia das plantas cultivadas na roça. Em termos evolutivos, o agrupamento das diferentes variedades facilita a sua recombinação, aumentando a chance de novas variedades surgirem. $\bigcirc$ trabalho exemplifica como é importante preservar a diversidade cultural de populações tradicionais, dentre outras razões, por guardarem formas de manejo singulares e desconhecidas em temas amplamente estudados

Palavras-chave: Índio - Conservação on farm - Mandioca - Ritos - Mitos.

\section{Introdução}

O homem é o ser na natureza responsável pelo paradoxo de "criar" e manter espécies e, ao mesmo tempo, depauperá-las e extingui-las. (Harlan \& De Wet 1973; Harlan 1975; Fernandez 2005).

Além da seleção natural, a domesticação de espécies pelo homem é uma forma clássica de geração e proliferação de espécies e variedades. Ao manejar as espécies de um dado local, o homem acaba privilegiando algumas, em

(*) Embrapa Recursos Genéticos e Biotecnologia. Brasília, DF. F.O. Freitas: fabiof@cenargen.embrapa.br S.B.B.C.Zarur sbzarur@cenargen.embrapa.br detrimento da diminuição ou mesmo, em casos extremos, chegando a eliminar localmente algumas nativas (Posey 1987; Blumler \& Byrne 1991; Balée 1994; Salick 1995).

Parte deste imenso poder de escolha do homem quanto a manter ou eliminar espécies, variedades e seus respectivos genótipos/alelos é inconsciente, e resulta de critérios subjetivos, como por exemplo, aqueles relacionados ao gosto, desejo, costume, preferências por determinada forma ou cor de fruto, dentro da diversidade disponível ao homem, num determinado local e momento (Harlan 1971; Harlan \& De Wet 1973; Brookfield, \& Padoch 1994).

Estas preferências e, principalmente, o esforço de conservar/perpetuar os tipos 
preferenciais (fenótipos), permitiram a criação de diversas raças locais. Ações de domesticação fizeram com que as diferenças culturais e de escolhas existentes entre as populações/etnias humanas, exercessem pressão diferencial sobre a diversidade das espécies disponíveis, se refletindo, como no caso abordado neste trabalho, em variedades de plantas cultivadas (Kerr 1987; Brookfield \& Padoch 1994; Bellon 1996; Salick et al. 1997; Peroni 1998; Amorozo 2000; Amorozo et al. 2002; Peroni \& Martins 2000).

Aliada à seleção humana, fatores ambientais, tais como o clima, temperatura, pluviosidade, pragas, competidores naturais, dentre outros, que são componentes de seleção natural, também atuam sobre as populações das espécies cultivadas, preservando variedades mais adaptadas (Harlan 1971; Harlan \& De Wet 1973; Darwin 1985; Harlan 1995).

Durante pelo menos os últimos 8.000 anos, a sobrevivência do homem esteve ligada à manutenção de seus cultivos tradicionais. Por outro lado, a perpetuação e a difusão de determinadas raças locais esteve também condicionada à perpetuação, migração e relações culturais de determinados grupos humanos, em ciclos contínuos de co-evolução. Sem as ações e atividades humanas, diversas raças locais teriam sido extintas, uma vez que dependem do homem para sobreviver e se reproduzir no ambiente de cultivo (Altieri \& Merrick 1987; Brookfield \& Padoch 1994; Brush 1995). O processo co-evolutivo é tão complexo que a conquista e colonização de muitos ambientes, pelo homem, reflete as características da própria planta, para que esta possa crescer e fornecer alimentos ao homem.

Deste convívio de co-evolução homemplanta, pode-se afirmar que: quanto maior a diversidade de culturas humanas, maior o potencial de geração e conservação de raças locais de uma dada espécie (Vavilov 1992). Por outro lado, o desaparecimento e a aculturação de grupos e sociedades humanas aumentam o risco de perda de espécies e raças locais (Freitas \& Freitas 2003, 2004; Freitas 2005).

Sabe-se que as populações indígenas foram e ainda são as principais guardiãs de grande número de raças locais de plantas e animais
(Brieger et al. 1958; Altieri \& Merrick 1987; Salick et al. 1997; Emperaire 2001). Entretanto, a dificuldade em manter esses recursos genéticos aumenta com a intensificação do contato com a sociedade envolvente (Freitas \& Freitas 2003; Freitas 2005).

Neste sentido, este trabalho apresenta um exemplo real de como uma tradição cultural influencia na amplificação/geração, seleção e manutenção da diversidade de uma espécie e suas raças locais.

\section{Objetivo}

O objetivo deste trabalho é descrever uma tradição cultural de alguns moradores da aldeia indígena Yawalapiti, que tem reflexo direto na conservação de raças locais de mandioca Manihot esculenta Crantz, e discutir o impacto desta forma de tradição em termos evolutivos, tanto na manutenção quanto na ampliação da diversidade daquela espécie agrícola.

\section{Material e método}

O trabalho foi realizado na aldeia Yawalapiti entre os anos de 2004 e 2006 (coordenadas geográficas: S 12 o 09 ' 987 ' e W 53 20 '103' ') que se localiza na chamada "boca" do rio Tuatuarí, afluente do rio Culuene, um dos principais formadores do rio Xingu. Ela se encontra no Parque Indígena do Xingu, na região nordeste do estado do Mato Grosso. A aldeia Yawalapiti possui aproximadamente 280 pessoas, distribuídas em 15 casas (ano 2004). Os Yawalapiti pertencem ao tronco lingüístico Aruak, do qual fazem parte também os Waurá e Mehinako, ambas as etnias residentes no mesmo Parque (Zarur 1986; Melatti 1998)

O método de trabalho consistiu na elaboração e aplicação de um questionário semi-estruturado em todas as casas daquela aldeia, preferencialmente com o casal responsável por cada casa, tendo sido complementado com a observação direta nas roças de cada uma dessas famílias (Amoroso et al. 2002; Viertler 2002). O objetivo principal era realizar um 
levantamento das espécies e variedades de plantas que cada família da aldeia cultivava durante a pesquisa.

\section{Resultados e discussão}

Entre os Yawalapiti cada família cultiva sua própria roça, com autonomia de escolha do local, do tamanho e, principalmente, das espécies e variedades plantadas, onde a mandioca é a principal espécie cultivada.

Conseqüentemente, cada família possui sua coleção particular de espécies e variedades, algumas sendo similares às de outras famílias, outras mais restritas e algumas exclusivas a uma família específica. As preferências pessoais, as relações familiares, as tradições e experiências de manejo sobre as espécies agrícolas determinam as características dessas coleções. Deste modo, além da variação na diversidade manejada por cada família, verificaram-se variações nas formas de plantio e de manejo praticadas por cada uma delas.

Em relação ao aspecto de plantio e manejo, observou-se uma tradição cultural praticada por uma única família daquela aldeia que repercute fortemente na conservação e na ampliação da diversidade de raças locais de mandioca, prática esta que descreveremos a seguir. Cabe ressaltar que esta família é a que possui uma das maiores diversidades de mandioca na aldeia.

A sua roça, como a da maioria das outras roças da aldeia é constituída basicamente pelo plantio da mandioca por propagação vegetativa, em manivas (pedaço do caule da planta), o que permite a perpetuação de um mesmo tipo (genótipo) indefinidamente, através das gerações. Tradicionalmente, nas roças em geral, as diferentes raças locais desta espécie são distribuídas de forma agrupada por tipos.

Existem dois grupos básicos de tipos de variedades de mandioca: um composto por tipos conhecidos como "doce", usado para mingau, normalmente plantado ao longo do perímetro limítrofe da roça, e o outro grupo, chamado de "polvilho", usado para fazer um tipo de pão, conhecido como beiju, plantado na parte interna da roça (Mühlen 1999). Estes dois grupos (doce/polvilho), por sua vez, apresentam diversos "tipos", ou variedades, que são plantados separadamente por setores das roças, em "montes" ou covas, em um espaçamento médio de dois por dois metros entre as covas.

Extrapolando o fator agrícola, pudemos observar nas roças da família do Senhor Tapaiê uma tradição cultural singular que é o tema deste trabalho. Além da distribuição comum às demais roças da aldeia, o principal aspecto distintivo da roça desta família é o fato de o agricultor construir dois montes ou covas, distantes mais ou menos $40 \mathrm{~m}$ um do outro, nos quais reúne, em cada um dos montes (Fig. 1), todos os tipos de mandioca que possui. Esses dois montes são denominados de "casa do Kukurro”, ou em uma tradução livre, casa do espírito da lagarta (a lagarta referida, segundo o agricultor, se alimenta comumente das folhas da planta da mandioca).

A casa do Kukurro, segundo o agricultor, é construída todo ano, após um ritual do qual participam os homens e as mulheres da família. Todos se pintam e cantam músicas, cujas letras evocam o espírito do Kukurro. Para eles, quem cuida da roça é o espírito do Kukurro. É este espírito que vai trazer força para que as plantas cresçam mais vigorosas. São dois montes porque são dois irmãos gêmeos, figuras fortes na Mitologia Xinguana (Villas Boas \& Villas Boas 1976; Novaes 1985; Ferreira 1994).

Ainda, "ligando" estes dois "irmãos" representados pelos montes, o agricultor pode fazer uma linha alta de terra $( \pm 40 \mathrm{~cm}$ de altura), em ziguezague, ao longo da qual ele também planta tipos de mandioca - neste caso normalmente dos tipos doces. Este ziguezague, segundo o agricultor, representa uma cobra, outra figura mítica e que, segundo ele, também ajuda a trazer proteção e força para a roça. Note que o agricultor na safra de 2004/05 não implantou esta linha/cobra, mas o fez na roça nova, no ciclo agrícola 2006/07, quando abandonou a casa do Kukurro anterior e fez outra na nova roça.

Esta observação pode demonstrar que, culturalmente, a "cobra" teria um papel secundário, e as covas-irmãos seriam o foco 


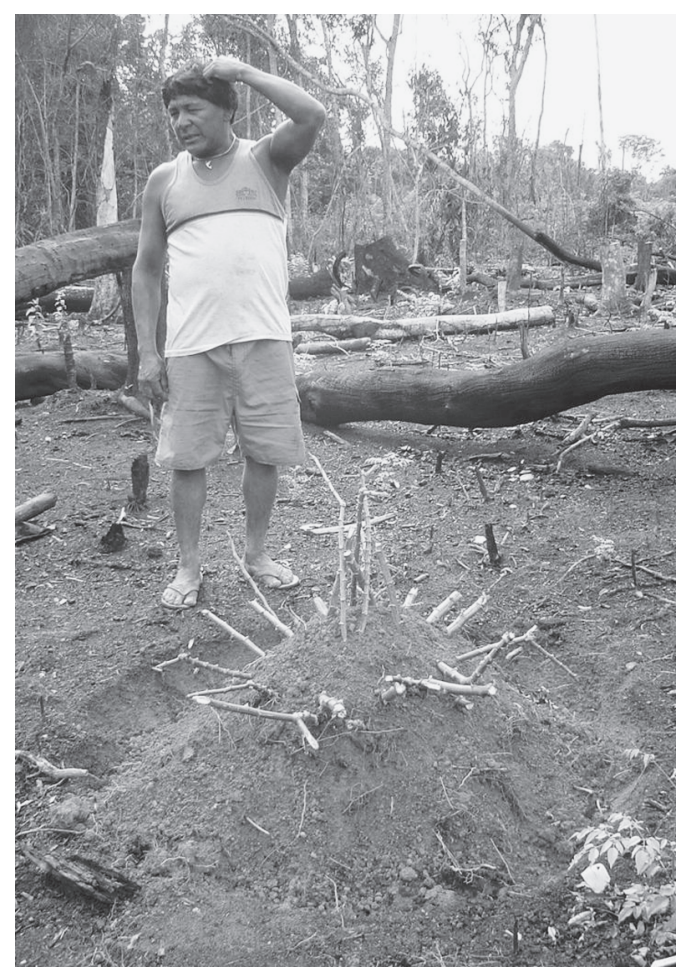

Fig. 1. Casa do Kukurro - monte de terra preparado pelo agricultor reunindo todas as variedades de mandioca manejadas pela família, com o intuito de trazer força para a sua roça.

principal. Entretanto, a disposição em formato de cobra pode ter conseqüências evolutivas para a mandioca, uma vez que traz tipos de mandioca que normalmente se localizam na margem da roça, para o interior da mesma, aumentando a chance de recombinação de tipos distintos (doce-polvilho).

Segundo o relato, corroborado pelas observações feitas em campo, a casa do Kukurro é sempre situada na parte nova da roça (aberta no ano agrícola corrente) perto do limite voltado para a mata e nunca próxima ao limite com a roça vizinha. A explicação para o distanciamento da roça vizinha é a de que a proximidade pode ter o efeito inverso, fazendo com que a energia, ao invés de proteger suas próprias plantas, passe para as plantas do vizinho, deixando a sua roça fraca.

Este ritual, prática muito antiga, era costume da tribo Waurá e foi trazido à aldeia Yawalapiti pelo casamento deste agricultor
Waurá, com a esposa Yawalapiti. A regra de residência adotada no Alto Xingu obedece ao costume de o marido se mudar para a casa do pai da esposa após o casamento (Zarur 1975). Reiteramos que ambas as etnias pertencem ao tronco lingüístico Aruak e possuem uma relação cultural muito antiga. É interessante notar que existe outro morador na aldeia Yawalapiti de origem Waurá e este não tem o costume de realizar esta prática em suas roças. A partir desta constatação, o agricultor Waurá em foco foi questionado do motivo de ser o único a realizar o ritual da casa do Kukurro. Este explicou que era uma prática muito antiga entre os Waurá, mas que o ritual na roça se perdeu ao longo do tempo, mantendo-se apenas a crença espiritual. Sua linha familiar, na aldeia Waurá, tinha sido a única a manter essa herança cultural dos ancestrais, com o viés agrícola. Isto explica o fato de o termo Kukurro não ser conhecido entre os Yawalapiti, mas ser conhecido pelos Waurá, ligado, de modo geral, a questões espirituais de cura de enfermidades e não como proteção ao cultivo agrícola da mandioca.

Segundo um outro morador da aldeia Waurá, com quem tivemos a chance de conversar, na Fundação Nacional do índio - FUNAI, a história do Kukurro como fonte de cura surgiu quando uma senhora muito idosa saiu sozinha de sua roça e ouviu um canto que parecia de gente. Ela viu o espírito dono da mandioca (uma lagarta pequenininha que come as folhas $\mathrm{da}$ mandioca) dançando na aldeia dos espíritos. A sua filha foi procurá-la e perguntou o que tinha acontecido e por que estava demorando a voltar para a aldeia. Segundo o relato, esta senhora contou o que presenciou e esta história foi difundida tanto entre os moradores da aldeia Waurá, como para as etnias Mehinaco e Aweti.

Segundo este último "informante", os moradores da aldeia Waurá realizam rituais para a cura de determinadas enfermidades (problemas para urinar, por exemplo), da seguinte forma: o pajé faz uma pajelança para ver qual é o espírito que está causando a doença, usando o zunidor. Corta-se madeira no mato para fazer a pá de beiju, e colhe-se 
mandioca na roça. Todos da família do enfermo dançam no pátio e nas casas e durante a dança oferecem peixe e beiju até o doente ficar bom.

As questões culturais da casa do Kukurro necessitam de um estudo antropológico mais específico, uma vez que não encontramos referências na literatura científica ao termo Kukurro e ainda menos as práticas agrícolas referentes a ele. Entretanto, o tema deste trabalho se restringe principalmente às implicações evolutivas desta tradição como geradora e conservadora da diversidade das variedades tradicionais de mandioca, como será aprofundado a seguir.

Focando novamente a roça do agricultor Waurá da aldeia Yawalapiti, ressaltamos que em cada um destes dois montes da casa do Kukurro, a família reúne e planta todos os tipos de mandioca de sua coleção, com três ou quatro manivas de cada tipo, seqüencialmente, no perímetro e na parte superior da cova, fazendo com que as duas covas tenham um raio maior do que os das demais covas da roça, como observado na Fig. 2.

Estes montes são os primeiros a serem plantados na roça e, posteriormente, são as últimas covas a serem colhidas. Como a época de colheita coincide com a do plantio do ano seguinte, este material serve como fonte de variedades para a nova roça, como um pequeno banco de germoplasma/depósito de variedades.

Em termos evolutivos, como todas as variedades são reunidas em um espaço restrito, potencializa-se a chance de recombinação entre os diferentes tipos/variedades locais. Este fato ocorre porque mesmo a espécie sendo comumente propagada vegetativamente pelo homem, ela não perdeu, ao longo de seu processo de domesticação, sua capacidade de reprodução sexual, assim como se observa com outras espécies domesticadas com padrões reprodutivos semelhantes, como a batata-doce (Ipomea batatas), inhame (Dioscorea ssp.), araruta (Maranta arundinacea) e taioba (Xanthosoma sagittifolium) (Cury 1993; Peroni \& Martins 2000; Silva 2000; Martins 2001). Ainda, sendo a espécie monóica, com flores

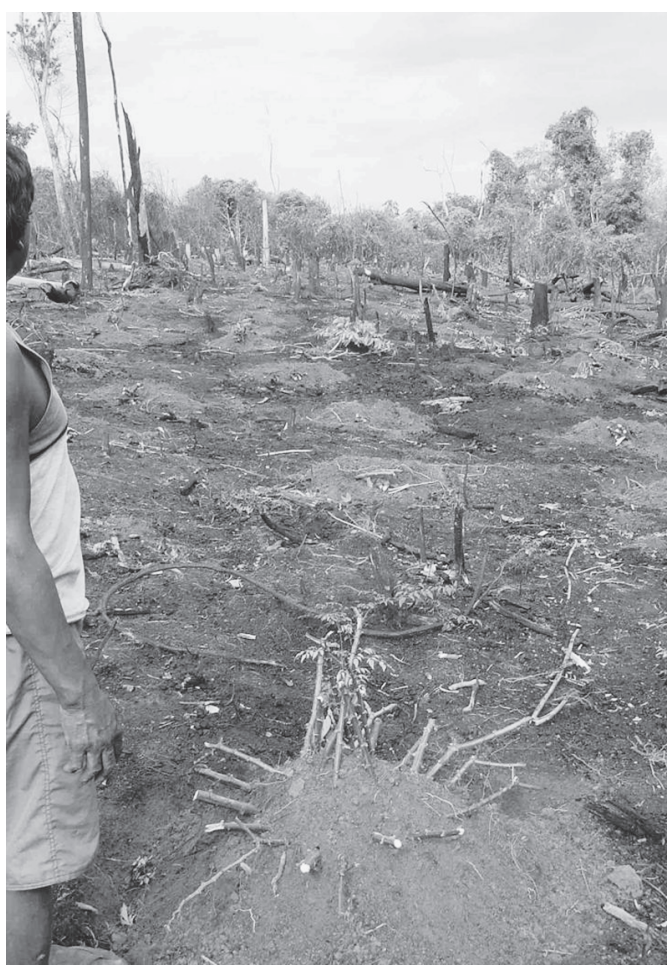

Fig. 2. Detalhe da casa do Kukurro, mostrando o arranjo singular da disposição das manivas de mandioca, mais com o intuito de design cerimonial do que agrícola.

masculinas e femininas separadas em uma mesma planta, as quais ainda possuem época de maturação diferente - protogenia/ protrandria, faz com que a chance de cruzamento, troca de gametas entre plantas distintas, aumente (Silva 2000).

Outro fato importante para a evolução e amplificação/geração de variabilidade desta espécie é o de aquele grupo doméstico reconhecer e manejar plantas de mandioca originadas via semente, nascidas espontaneamente. Por questões fisiológicas, as plantas via semente normalmente não produzem raízes tuberosas nos primeiros anos, fazendo com que sejam facilmente descartadas pela maioria dos outros agricultores indígenas do Parque, pois somente após o replantio assexual (vegetativo) desta planta originada por semente é que se pode realmente identificar o seu potencial, já que as raízes tuberosas só se desenvolvem após dois ou três ciclos de replantio. 
Este agricultor reconhece as plantas originadas por sementes, primeiramente por apresentarem as folhas cotiledonares, podendo posteriormente confirmar pela presença de raiz pivotante e não tuberosa. Segundo aquele agricultor, ele identifica estas plantas originadas por semente e cuida delas, replantando-as por pelo menos três ciclos agrícolas consecutivos, a fim de permitir a formação da raiz tuberosa e, portanto, possibilitando-lhe avaliar o potencial alimentar da planta. Uma vez avaliada, a planta pode ser descartada ou incorporada à sua coleção. Neste último caso, ele a batiza, utilizando características morfológicas, do ciclo, místico/cultural ou características alimentares, apresentadas por este novo tipo, como acontece também entre outros grupos humanos, por exemplo entre os Caiçaras (Peroni 1998; Peroni \& Martins 2000).

Ainda, como a forma usual de propagação da espécie pelo agricultor é a forma vegetativa, por manivas, qualquer genótipo novo, uma vez selecionado, é facilmente multiplicado e fixado à coleção. Isto é muito interessante, pois quando genótipos superiores forem identificados, estes podem ser perpetuados indefinidamente, clonados por meio da reprodução vegetativa, sem que ocorra segregação de seus alelos.

Resumindo, o fato de aquela família manter esta tradição cultural denominada casa do Kukurro, faz com que:

- Todas as variedades da coleção familiar sejam plantadas lado a lado e em duplicata;

- Potencialize a chance de cruzamento entre as diferentes variedades locais manejadas pela família do agricultor, pela aproximação de variedades que normalmente ficam separadas;

- Maneje e selecione plantas originadas via reprodução sexual, podendo incorporar novos genótipos à sua coleção, inclusive através de recombinação com parentes silvestres encontrados na mata adjacente;
- Promova uma forma de conservação local (in situ sob-cultivo), a qual, tanto fortalece a chance de preservação dos cultivos da coleção mantida pela família, como favorece o aparecimento de novos materiais, incrementando a diversidade ali existente, reforçando modelos evolutivos já sugeridos para a espécie (Martins 2001)

\section{Considerações finais}

Neste trabalho, apresentamos uma tradição cultural com implicação direta na diversidade de espécies agrícolas manejadas por agricultores indígenas. Esta tradição funciona, tanto como um mini-banco de germoplasma in situ, como fonte contínua de diversidade, devido ao dinamismo e ao manejo, por parte do agricultor. Possibilita, conseqüentemente, geração e adequação de novos genótipos às características ambientais, também dinâmicas. Ainda, esta prática pode servir para estruturar modelos que sirvam em projetos de conservação in situ sob-cultivo (on farm). Enfatizamos a importância da diversidade étnica e cultural e de incentivos que a valorizem, pois é por meio desta diversidade que temos a chance de encontrar práticas singulares, dentre temas exaustivamente explorados, como essa forma peculiar de plantio de um cultivo tão popular no Brasil como a mandioca. Cabe a estudos futuros determinar a causa do desaparecimento desta tradição (se por fatores externos ou internos à cultura Xinguana) e, ao mesmo tempo, valorizar e reconhecer os agricultores que ainda a praticam.

\section{Agradecimentos}

Agradecemos a Tapaiê Waurá e sua família, que gentilmente nos apresentaram esta tradição cultural, aqui compartilhada. Apoio: Programa Biodiversidade Brasil-Itália. 
FREITAS, F.O.; ZARUR, S.B.B.C. Kukurro house - cultural tradition and its influence in the amplification and maintenance of the diversity in a crop field. Revista do Museu de Arqueologia e Etnologia, São Paulo, 17: 381-389, 2007.

\begin{abstract}
This work presents for the first time a cultural tradition, which has a strong impact on the management of alimentary diversity by Indians from the Xingu Indigenous Park. Knowing as "Kukurro house", or house of the spirit of the caterpillar/larva, this tradition consists of planting together all the varieties of manioc - Manihot esculenta Crantz, cultivated by the farmer, in two mounts or hollows. It is believed that this tradition fortifies and gives energy to the plants in the field. In evolutionary terms, the grouping of the different varieties facilitates their recombination, increasing the possibility of new varieties to appear. It shows how it is important to preserve cultural diversity of traditional populations, among other things as a way to know about singular forms of handling that still exist unknown inside a widely studied subject.
\end{abstract}

Keywords: Indigenous people - On farm conservation - Manioc Rites - Myths.

\title{
Referências bibliográficas
}

ALTIERI, M.A.; MERRICK, M.A.

1987 In situ conservation of crop genetic resources through maintenance of traditional farming systems. Economic Botany, 41: 86-96.

AMOROZO, M.C.M.

2000 Management and conservation of Manihot esculenta Crantz germplasm by traditional farmers in Santo Antonio do Leverger, Mato Grosso State, Brazil. Etnoecologica, 4 (6): 69-83.

AMOROZO, M.C.M.A.; MING, L.C.; SILVA, S.M.P.

2002 Métodos de Coleta e Análise de Dados em Etnobiologia, Etnoecologia e Disciplinas Correlatas. Rio Claro: Unesp/CNPq Editores.

BALÉE, W.

1994 Footprints of the forest: $K a^{\prime}$ apor ethnobotany: The historical ecology of plant utilization by an Amazonian people. New York: Columbia University Press.

BELLON, M.R.

1996 The dynamics of crop infraespecific diversity: a conceptual framework at the farmer level. Economic Botany, 50: 26-39. BLUMLER, M.A.; BYRNE, R.

1991 The ecological genetics of domestication and the origins of agriculture. Current Anthropology, 32 (1): 23-66.

BRIEGER, F.G.; GURGEL, J.T.A.; PATERNIANI, E.; BLUMENSCHEIN, A.; ALLEONI, M.R.,

1958 Races of maize in Brazil and other Eastern South American countries. Washington, D.C.: National Academy of SciencesNational Research Council.

BROOKFIELD, H.; PADOCH, C.

1994 Appreating agrodiversity: A look at the dynamism and diversity of indigenous farming practices. Environment, 36 (5): 6-45.

BRUSH, S.B.

1995 In situ conservation of landraces in Centers of Crop Diversity. Crop Science, 35 (2): 346-354.

CURY, R.

1993 Dinâmica evolutiva e caracterização de germoplasma de mandioca (Manihot 
esculenta, Crantz) na agricultura autóctone. Tese de Mestrado. Piracicaba, ESALQ-USP. 103 p.

DARWIN, C.

1985 A origem das espécies. Belo Horizonte: Itatiaia.

EMPERAIRE, L.

2001 Elementos de discussão sobre a conservação da agrobiodiversidade: o exemplo da mandioca (Manihot esculenta Crantz) na

Amazônia brasileira. In: Capobianco, J.P.

(Ed.) Biodiversidade da Amazônia. São

Paulo, Estação Liberdade/ISA: 225-234.

FERNANDEZ, F.

2005 Aprendendo a lição de Chaco Canyon: do desenvolvimento sustentável a uma vida sustentável. Reflexão, 6 (15): 1-20.

FERREIRA, M.K.L.

1994 Histórias do Xingu. São Paulo: NHII/USP e FAPESP editoras.

FREITAS, F.O.

2005 Sementes crioulas: uma abordagem em comunidades indígenas. Comunicado Técnico Embrapa, 127.

FREITAS, F.O.; FREITAS, J.Z.

2003 Relato sobre mudanças alimentares culturais em comunidades no Parque Indígena do Xingu. Boletim de Pesquisa e Desenvolvimento Embrapa, 50.

FREITAS, J.Z.F.; FREITAS, F.O.

2004 A Influência da mudança do hábito alimentar na prevalência de diabetes na área indígena Xavante: Estudo de caso: Reserva Indígena São Marcos. Boletim de Pesquisa Embrapa, 59.

HARLAN, J.R.

1971 Agricultural origins: centers and noncenters. Science, 174: 468-473.

1975 Crops and Man. Madison: American Society of Agronomy/ Crop Science

SOCIETY OF AMERICA.

1995 The living fields: our agricultural heritage. Cambridge: University Press.

HARLAN, J.R.; DE WET, J.M.J.

1973 On the quality of evidence for origin and dispersal of cultivated plants. Current Antropology, 14: 51-55.

KERR, W.E.

1987 Agricultura e seleção genética de plantas. In: Ribeiro, D. (Ed.) Suma Etnológica Brasileira. Petrópolis, Editora Vozes, 1:159-171.

MARTINS, P.S.

2001 Dinâmica evolutiva em roças de caboclos amazônicos. In: Vieira, I.C.G.; Silva,
J.M.C.; Oren, D.C.; D'Incao, M.A. (Eds.) Diversidade biológica e cultural da Amazônia. Belém, Museu Paraense Emílio Goeldi: 369-384.

MELATTI, J.C.

1998 Índios da América do Sul - Áreas etnográficas. Brasília: Universidade de Brasília. Volume E: 17-23.

MÜHLEN, G.S.

1999 Avaliação da diversidade genética de etnovariedades de mandioca (Manihot esculenta Crantz) com marcadores de DNA: RAPD, AFLP e microssatélites. Tese de Doutorado. Piracicaba, ESALQUSP. 176 p.

NOVAES, W.

1985 Xingu - uma flecha no coração. São Paulo: Editora Brasiliense S.A.

PERONI, N.

1998 Taxonomia folk e diversidade intraespecífica de mandioca (Manihot esculenta Crantz) em roças de agricultura tradicional em áreas de Mata Atlântica do Sul do Estado de São Paulo. Dissertação de mestrado. Piracicaba, ESALQ-USP. $191 \mathrm{p}$.

PERONI, N.; MARTINS, P.S.

2000 Influência da dinâmica agrícola itinerante na geração de diversidade de etnovariedades cultivadas vegetativamente. Interciencia, 25 (1): 22-29.

POSEY, D.A.

1987 Manejo da floresta secundária, capoeiras, campos e cerrados (Kayapó). In: Ribeiro, D. (Ed.) Suma Etnológica Brasileira. Petrópolis, Editora Vozes, 1: 173-185.

SALICK, J.

1995 Toward an integration of evolutionary ecology and economic botany: personal perspectives on plant/people interactions. Annals of the Missouri Botanic Garden, 82 (1): 25-33.

SALICK, J.; CELLINESE, N.; KNAPP, S.

1997 Indigenous diversity of cassava: generation, maintenance, use and loss among the Amuesha, Peruvian upper Amazon. Economic Botany, 51: 7-17.

SILVA, R.M.

2000 Sistema reprodutivo, fluxo gênico e paternidade em roça de etnovariedades de mandioca (Manihot esculenta Crantz). Tese de Doutorado. Piracicaba, ESALQ-USP. 131p. VAVILOV, N.I.

1992 Centros de origem das plantas cultivadas. Jaboticabal: Funep: Fcav/Unesp. 
VILLAS BOAS, O; VILLAS BOAS, C.

1976 Xingu - os indios, seus mitos. Rio de Janeiro: Zahar Editores.

ZARUR, G.C.L.

1975 Parentesco, Ritual e Economia no Alto Xingu. Brasília: FUNAI.
1986 Ecologia e cultura: Algumas comparações. In: Ribeiro, D. (Ed.) Suma Etnológica Brasileira. Petrópolis, Editora Vozes, 1: 273-280.

Recebido para publicação em 30 de maio de 2007. 